\title{
Geschichte der lateinischen Sprache
}

von

Prof. Dr. Friedrich Stolz u. Prof. D. Dr. Albert Debrunner

Vierte stark umgearbeitete Auflage von

Dr. Wolfgang P. Schmid

ord.Professor an der Universität Göttingen

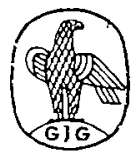

Sammlung Göschen Band 492/492 a

Walter de Gruyter \& Co. · Berlin 1966

vormals G. J. Göschen'sche Verlagshandlung - J. Guttentag, Verlagsbuchhandlung - Georg Reimer - Karl $J$. Trübner · Veit \& Comp. 
(C)

Copyright 1966 by WaIter de Gruyter \& Co., vormals G. J. Göschen'sche Verlagshandlung - J. Guttentag, Verlagsbuchhandlung - Georg Reimer Karl J. Trübner - Veit \& Comp., Berlin 30. - Alle Rechte, einschl. der • Rechte der Herstellung von Photokopien und Mikrofilmen, von der Verlagshandlung vorbehalten. - Archiv-Nr.: 7310664 - Satz und Druck: J.J. Augustin, Glückstadt - Printed in Germany. 